\title{
Conversion of sugars to methyl lactate with exfoliated layered stannosilicate UZAR-S4
}

\author{
Beatriz Murillo $^{\mathrm{a}}$, Óscar de la Iglesia ${ }^{\mathrm{a}, \mathrm{b}}$, César Rubio ${ }^{\mathrm{a}}$, Joaquín Coronas ${ }^{\mathrm{a}}$, Carlos Téllez ${ }^{\mathrm{a}, *}$ \\ a Instituto de Nanociencia de Aragón (INA), Instituto de Ciencia de Materiales de Aragón (ICMA) and Department of Chemical and Environmental Engineering, Universidad \\ de Zaragoza-CSIC, 50018, Zaragoza, Spain \\ ${ }^{\mathrm{b}}$ Centro Universitario de la Defensa Zaragoza, Academia General Militar, 50090, Zaragoza, Spain
}

\section{A R T I C L E I N F O}

\section{Keywords:}

Heterogeneous catalysis

Sugar conversion

Lactic acid

Layered stannosilicate

Exfoliated material

\begin{abstract}
A B S T R A C T
Biomass has been shown as an alternative to fossil fuels for obtaining chemicals. In this work, the transformation of sugars into methyl lactate (ML) at $160{ }^{\circ} \mathrm{C}$ was carried out using the layered stannosilicate UZAR-S3 (University of Zaragoza-solid number 3) and the delaminated material UZAR-S4 (University of Zaragoza-solid number 4) obtained from its exfoliation. The exfoliation of UZAR-S3 to UZAR-S4 increased the accessibility of the compounds to the catalytic sites and the medium-strength acidity. Thus, the yield to ML for sucrose transformation increased from $8 \%$ for UZAR-S3 to $49.9 \%$ for UZAR-S4. In the reusability tests, the UZAR-S4 catalyst was characterized before and after reaction by several techniques such as X-ray diffraction, thermogravimetry analysis, scanning electronic microscopy, energy dispersive X-ray spectroscopy and nitrogen adsorption. A deactivation of the catalyst was observed, which was related to carbonaceous deposits that decreased the specific surface area and the pore volume of the catalyst.
\end{abstract}

\section{Introduction}

In the last decades the transformation of renewable biomass to generate energy or added value products has become a field of growing interest for many researchers because of uncertainty about fossil resources and environmental concerns. Among the variety of products that can be obtained from biomass, lactic acid is of significant importance due to its ability to serve as a platform chemical for a wide range of applications in the chemical, pharmaceutical, cosmetics and food industries [1]. Beyond its traditional uses, currently there is an increased demand for lactic acid as a feedstock for the production of biopolymer poly-lactic acid (PLA), which is a promising biodegradable, biocompatible, and environmentally friendly alternative to plastics derived from petrochemicals [2]. PLA can be used to produce commercial products related to packaging, agricultural uses, transportation, electronics and houseware, among others [3].

The main way for the production of lactic acid is by means of the fermentation of carbohydrates (usually pentoses or hexoses) in aqueous solutions. Nevertheless, nutrient costs, gypsum waste produced in the neutralization step and low volumetric productivities are major drawbacks of this process [4]. Furthermore, the purification of lactic acid from aqueous solutions is a complex process since it involves the esterification of lactic acid with an alcohol to obtain the corresponding alkyl lactate, distillation and subsequent hydrolysis, which suppose a high energy cost [5].

As an alternative to fermentation, catalytic conversion of carbohydrates for the production of lactic acid arose as process worth studying. In fact, first with homogeneous catalysts, Hayashi et al. reported the pioneering catalytic conversion of trioses to lactic acid with a Sn halide [6]. Since then, the use of other homogeneous catalysts have been reported such as $\mathrm{SnCl}_{4}$ [7] or $\mathrm{Sn}^{4+}$-based organometallic complexes [8].

On the other hand, the use of a heterogeneous catalytic process facilitates the recovery of the catalyst after reaction and its later reuse. In this context, Janssen et al. [9], used various FAU-type zeolites in ethanol for the conversion of trioses reaching a yield to ethyl lactate up to $65 \%$ after $6 \mathrm{~h}$ at $90^{\circ} \mathrm{C}$. Other Sn-based catalysts were applied to the conversion of trioses to lactic acid or alkyl lactates, for instance, Sn-MFI [10], Sn-MCM-41 [10-12], Sn-SBA-15 [10], Sn-MWW [13], Sn-Si mixed oxides [14] or recently $\mathrm{Sn}-\mathrm{Nb}$ mixed oxides [15], the last catalysts with methyl lactate yield of $98 \%$ after $2 \mathrm{~h}$ at $140{ }^{\circ} \mathrm{C}$. Further, other metal oxide without tin (e.g. $\gamma-\mathrm{Al}_{2} \mathrm{O}_{3}$ [16] or $\mathrm{Nb}_{2} \mathrm{O}_{5}$ [17]) or metal phosphates (e.g. with Sn [18] or Nb [19]) have been tested for the conversion of dihydroxyacetone to lactic acid derivates. In last catalysts using tin phosphates, Wang et al. [18] have reached yield of $96 \%$ of lactic acid after $4 \mathrm{~h}$ at $140^{\circ} \mathrm{C}$.

While the conversion of trioses to lactic acid or alkyl lactates

\footnotetext{
* Corresponding author.

E-mail address: ctellez@unizar.es (C. Téllez).
} 
provides a solid test for benchmarking catalysts, the use of abundant hexoses (glucose or fructose) or even di- or polysaccharides (sucrose) is industrially preferred [20]. To carry out these reactions, higher reaction temperatures are required $\left(\geq 150^{\circ} \mathrm{C}\right)$ in comparison with those applied to trioses (usually $\pm 90^{\circ} \mathrm{C}$ ). This results in more side reactions, and consequently lower yields to lactic acid or alkyl lactates are obtained [4]. Holm et al. [21] reported the conversion of sucrose to alkyl lactates using zeolites Ti-Beta, Zr-Beta and Sn-Beta with a maximum yield of ML of $64 \%$ at $160{ }^{\circ} \mathrm{C}$ for $20 \mathrm{~h}$. Recently, other authors have reported the utilization of a carbon-silica composite [11], Sn-MWW-type zeolite [13], hierarchical zeolite Sn-Beta [22], Fe-doped $\mathrm{SnO}_{2}$ [23], Mg-MOF74 [24] or $\gamma$-NiOOH [25], among others. In previous works, we also applied several metal organic frameworks: Zn imidazolate ZIF-8 [26] and Sn-based carboxylates UZAR-S10 and MIP-177-LT (Ti/Sn) [27] for this reaction with good results.

Layered silicates represent a very attractive field of research because of the advantages of layered materials as active catalysts [28]. A characteristic feature of some layered materials is their ability to swelling and delamination, processes that involve the intercalation of guest molecules to increase the interlayer space and subsequent exfoliation.

In a previous work, we reported the use of delaminated materials UZAR-S1 and UZAR-S2 in the catalytic conversion of glucose with an increase of methyl lactate yield with respect to their precursor materials, microporous titanosilicates JDF-L1 and AM-4, respectively, since they provided a better access of the reactants to catalytic sites, thus increasing the catalytic activity of the materials but with low methyl lactate yields, below 6\% [29].

In this work the delaminated stannosilicate UZAR-S4 was applied as catalyst to the conversion of glucose and sucrose to methyl lactate. Tin containing catalysts have been shown in the literature as active and selective for this reaction $[10,27]$. USAR-S4, that was previously synthesized in our group [30], is obtained from the exfoliation of USAR-S3 which consists of $\mathrm{SiO}_{4}$ tetrahedral units observed by ${ }^{29} \mathrm{Si}$ NMR and octahedra $\mathrm{SnO}_{6}$ observed by ${ }^{119} \mathrm{Sn}$ NMR, therefore these materials belong to the so-called OPT family (Octahedral-Pentahedral-Tetrahedral (OPT) framework silicates) [31].

\section{Materials and methods}

\subsection{Synthesis of catalysts}

UZAR-S4 was prepared as reported elsewhere [30] by delamination of stannosilicate UZAR-S3. For the synthesis of UZAR-S3 a sodium silicate solution (27 wt $\% \mathrm{SiO}_{2}, 8 \mathrm{wt} \% \mathrm{Na}_{2} \mathrm{O}$, Merck) was mixed with deionized water and $\mathrm{NaOH}$ (98 wt\%, Sigma-Aldrich), afterwards tin(II) chloride dihydrate (reagent grade $98 \mathrm{wt} \%$, Sigma-Aldrich) was added. The molar composition of this gel was: $4.2 \mathrm{Na}_{2} \mathrm{O}: 1 \mathrm{SnCl}_{2}: 2.9 \mathrm{SiO}_{2}: 101$ $\mathrm{H}_{2} \mathrm{O}$. The gel was stirred for $1.5 \mathrm{~h}$ at room temperature and degassed for a few minutes in an ultrasound bath. The crystallization was carried out in a $40 \mathrm{~mL}$ Teflon-lined autoclave under hydrothermal conditions at $230^{\circ} \mathrm{C}$ for $96 \mathrm{~h}$. The obtained powder was filtered, washed repeatedly with deionized water and dried at $100^{\circ} \mathrm{C}$ overnight.

UZAR-S3 was proton exchanged and subsequently swollen by the intercalation of nonylamine molecules. For the proton exchange, the powder was immersed in a solution of water and acetic acid (glacial acetic acid in deionized water, $\mathrm{pH}=2.7$ ) for $10 \mathrm{~min}$, the $\mathrm{pH}$ reaching a value of 3.9. Then, a solution of nonylamine was added and the reaction was carried out under reflux at $60^{\circ} \mathrm{C}$ for $14 \mathrm{~h}$ at a constant $\mathrm{pH} 9.6$. Swollen UZAR-S3 was recovered by centrifugation and dried at $70{ }^{\circ} \mathrm{C}$ for $3 \mathrm{~h}$.

Finally, UZAR-S4 was obtained by extracting the amine with an $\mathrm{HCl} / \mathrm{H}_{2} \mathrm{O}$ /ethanol solution (5:15:870, molar ratio) under reflux at $55^{\circ} \mathrm{C}$ for $8 \mathrm{~h}$. After this time, the solid was recovered, washed 5 times with deionized water and dried at $100{ }^{\circ} \mathrm{C}$ for $12 \mathrm{~h}$. More details of the synthesis of catalysts can be found in a previous publication [30].

\subsection{Catalyst characterization}

Phase identification was carried out by a D-Max 2500 Rigaku X-ray diffractometer with a copper anode and a graphite monochromator using Cu-K $\alpha_{1}$ radiation $\left(\lambda=1.5418 \AA\right.$ ), taking data from $2 \theta=5^{\circ}$ to $40^{\circ}$ at a scan rate of $0.03^{\circ} \mathrm{s}^{-1}$ and operating parameters of $40 \mathrm{kV}$ and $80 \mathrm{~mA}$.

Nitrogen adsorption-desorption isotherms were obtained with a Micromeritics Tristar 3000 at $-196^{\circ} \mathrm{C}$. Before these measurements, the samples were degassed at $200^{\circ} \mathrm{C}$, during $8 \mathrm{~h}$ under vacuum. The specific surface area was calculated using the Brunauer-Emmett-Teller (BET) equation.

Thermal behavior was determined by thermogravimetric analysis (TGA) which was carried out using a Mettler Toledo TGA/SDTA $851^{\mathrm{e}}$ system. Samples (about $5 \mathrm{mg}$ ) were placed in $70 \mathrm{~mL}$ alumina pans and then heated under air flow up to $800^{\circ} \mathrm{C}$ at a heating rate of $10^{\circ} \mathrm{C} \cdot \mathrm{min}^{-1}$. Finally, scanning electronic microscopy (SEM) and energy dispersive $\mathrm{X}$ ray spectroscopy (EDX) were performed over Pt-coated specimens using an Inspect F50 model scanning electron microscope (FEI).

Pyridine FTIR was used to evidence the presence of Brønsted and Lewis acidic sites. UZAR-S3 and UZAR-S4, previously dried at $100{ }^{\circ} \mathrm{C}$ overnight, were exposed for adsorption to the pyridine vapor for $24 \mathrm{~h}$ at ambient temperature. After this adsorption step, the catalyst samples were exposed to a nitrogen stream of $50 \mathrm{~m} \mathrm{~L}(\mathrm{STP}) \cdot \mathrm{min}^{-1}$ at $80^{\circ} \mathrm{C}$ for $30 \mathrm{~min}$ to remove the physisorbed pyridine. FTIR spectra were achieved with a Vertex 70 of Bruker and a Specac's Golden Gate ATR.

Temperature-programmed desorption studies of $\mathrm{NH}_{3}\left(\mathrm{NH}_{3}\right.$-TPD) were performed for UZAR-S3 and UZAR-S4. These analyzes have been carried out in the Micromeritics AUTOCHEM II 2920 unit with thermal conductivity detector. The test conditions have been as follows. First, samples were dried in a He stream of $50 \mathrm{~m} \mathrm{L(STP)} \cdot \mathrm{min}^{-1}$ up to $200^{\circ} \mathrm{C}$ at $10^{\circ} \mathrm{C} \mathrm{min}{ }^{-1}$ and an isothermal time of $60 \mathrm{~min}$. After cooling the samples to $100{ }^{\circ} \mathrm{C}$, in $\mathrm{He} 50 \mathrm{~mL}(\mathrm{STP}) \cdot \mathrm{min}^{-1}$, the adsorption step was carried out with a stream of $50 \mathrm{~m} \mathrm{~L}(\mathrm{STP}) \cdot \mathrm{min}^{-1}$ of $0.5 \% \mathrm{NH}_{3} / \mathrm{He}$ at $100{ }^{\circ} \mathrm{C}$ for $1 \mathrm{~h}$. For the correct desorption of the physisorbed adsorbate, a He stream of $50 \mathrm{~m} \mathrm{L(STP)} \cdot \mathrm{min}^{-1}$ was passed through at $100^{\circ} \mathrm{C}$ for $1 \mathrm{~h}$. Finally, desorption of the adsorbate was analyzed with a He stream of $50 \mathrm{~m} \mathrm{~L}(\mathrm{STP}) \cdot \mathrm{min}^{-1}$ upon heating up to $700^{\circ} \mathrm{C}$ at $10^{\circ} \mathrm{C} \cdot \mathrm{min}^{-1}$.

\subsection{Catalytic tests}

Conversion of sugars to methyl lactate was performed in $35 \mathrm{~m} \mathrm{~L}$ Teflon-lined autoclave. For the catalytic tests $225 \mathrm{mg}$ of $\mathrm{D}-(+)$-glucose ( $99 \mathrm{wt} \%$, Alfa Aesar) or sucrose ( $99 \mathrm{wt} \%$, Sigma-Aldrich), $8.0 \mathrm{~g}$ of methanol (Multisolvent HPLC grade, Scharlau), $160 \mathrm{mg}$ of catalyst and $30 \mathrm{mg}$ of naphthalene ( $99 \mathrm{wt} \%$, Sigma-Aldrich), as internal standard, were added to the autoclave. Then, the mixture was heated to $160^{\circ} \mathrm{C}$ for $20 \mathrm{~h}$ in a rotary oven at $15 \mathrm{rpm}$. Finished the reaction time, the catalyst was recovered by centrifugation and dried in an oven at $70^{\circ} \mathrm{C}$ overnight prior to its reutilization.

The determination of products in the reaction liquid was carried out in the Gas Chromatograph (Agilent 6850 ) equipped with a capillary column HP-5MS $(30 \mathrm{~m} \times 0.250 \mathrm{~mm} \times 0.25 \mu \mathrm{m})$. The equipment is coupled with an Agilent 5975C mass spectrometry detector. The amount of different compounds was determined based on the internal standard of naphthalene using the calibration curves made with the commercial compounds methyl-S-(-)-lactate (ML, $98 \mathrm{wt} \%$, SigmaAldrich), methyl glycolate (MG, $98 \mathrm{wt} \%$, Alfa Aesar), pyruvaldehyde dimethyl acetal (PADA, $97 \mathrm{wt} \%$, Sigma-Aldrich), and 1,1,2,2-tetramethoxypropane (TMP, $99 \mathrm{wt} \%$, Sigma-Aldrich). Unidentified compounds detectable by GC-MS were calculated from the response factor of the methyl lactate, while the reaction yields were calculated on a carbon basis. On the other hand, sugars were determined using a commercial analytical method (sucrose/fructose/D-glucose Assay Kit, Megazyme). The concentration of sugar is related with that of reduced nicotinamide adenine dinucleotide phosphate (NADPH), which has a 


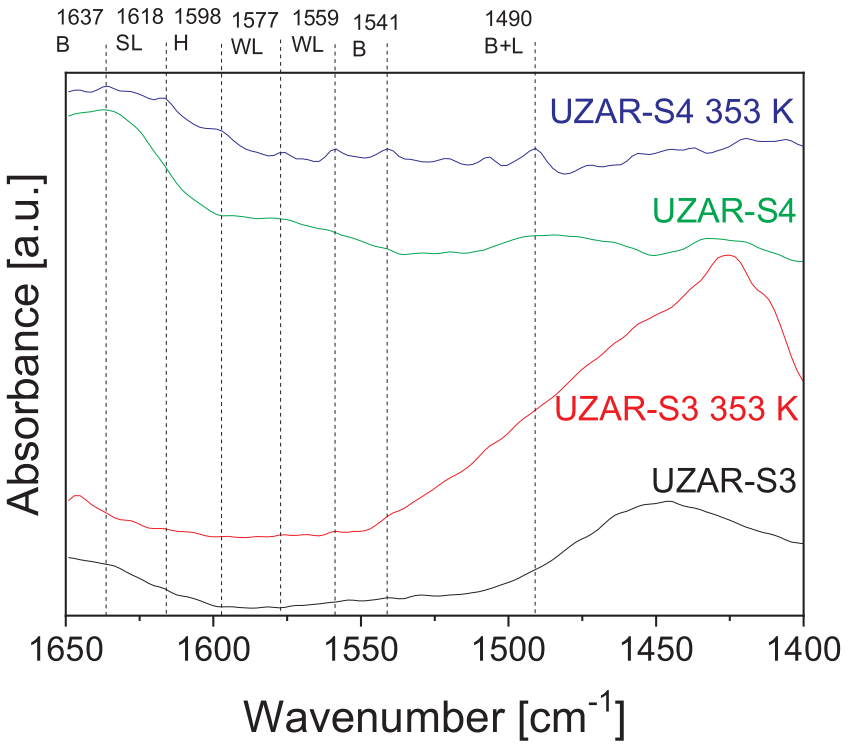

Fig. 1. FTIR spectra of UZAR-S3 and UZAR-S4 as made, and UZAR-S3 and UZAR-S4 after pyridine adsorption and heating at $353 \mathrm{~K}$.

specific absorbance band at $340 \mathrm{~nm}$. The variation of absorbance was measured using a V-670 Jasco UV-vis spectrophotometer.

\section{Results and discussion}

\subsection{Characterization of catalyst}

The preparation and characterization of materials UZAR-S3 and UZAR-S4 were previously reported [30]. In this work, the same preparation procedure was reproduced: first the synthesis of the layered material UZAR-S3, after its swelling with nonylamine to obtain swollen UZAR-S3 and finally the delamination of the latter by extraction with hydrochloric acid in a mixture of solvents (ethanol and water) to obtain UZAR-S4. Only the concentration of ethanol in the extraction solution (from $\mathrm{HCl} / \mathrm{H}_{2} \mathrm{O}$ /ethanol 5:17:870 to 5:15:870 here) has been slightly varied to favor the nonylamine extraction and therefore the process of delamination. With this slight variation, the average specific surface value of the three prepared samples of UZAR-S4 is $352 \pm 38 \mathrm{~m}^{2} \cdot \mathrm{g}^{-1}$, slightly higher than the highest value reported in [30] of $269 \mathrm{~m}^{2} \cdot \mathrm{g}^{-1}$.

In order to understand the acidity of UZAR-S3 and UZAR-S4, pyridine FTIR and $\mathrm{NH}_{3}$-TPD analyzes were performed. Fig. 1 shows the FTIR spectra before and after pyridine adsorption from UZAR-S3 and UZAR-S4.

In the case of UZAR-S4, several peaks are appreciated after pyridine adsorption. The peak at $1618 \mathrm{~cm}^{-1}$ is due to strong Lewis acid sites (SL) [23] while peaks at $1577 \mathrm{~cm}^{-1}$ and $1559 \mathrm{~cm}^{-1}$ correspond to weak Lewis acid sites (WL). The band centered at $1490 \mathrm{~cm}^{-1}$ indicates that pyridine may be coordinated with Lewis acid sites, while protonated pyridine would be interacting with Brønsted acid sites (B + L) [32]. At $1598 \mathrm{~cm}^{-1}$ there is a peak due to the hydrogen bond interaction between pyridine and the catalyst surface $(\mathrm{H})$ [23]. In addition, there are two more peaks that correspond to the Brønsted acid sites (B) at $1637 \mathrm{~cm}^{-1}$ and $1541 \mathrm{~cm}^{-1}$ [32]. The presence of both Brønsted and Lewis acid sites, coming, respectively, from silanol groups and metal vacant orbitals, would make UZAR-S4 suitable for obtaining methyl lactate as observed by other authors in their catalysts [23].

On the other hand, no significant bands of adsorbed pyridine are observed in UZAR-S3. This may be due to the fact that: i) pyridine, with a kinetic diameter of $5.7 \AA$ [33], cannot penetrate into the UZAR-S3 pores (nitrogen cannot go inside the pores) because it is not delaminated and does not have access, ii) the delaminated material UZAR-S4 is rich in high aspect ratio particles with a higher concentration of

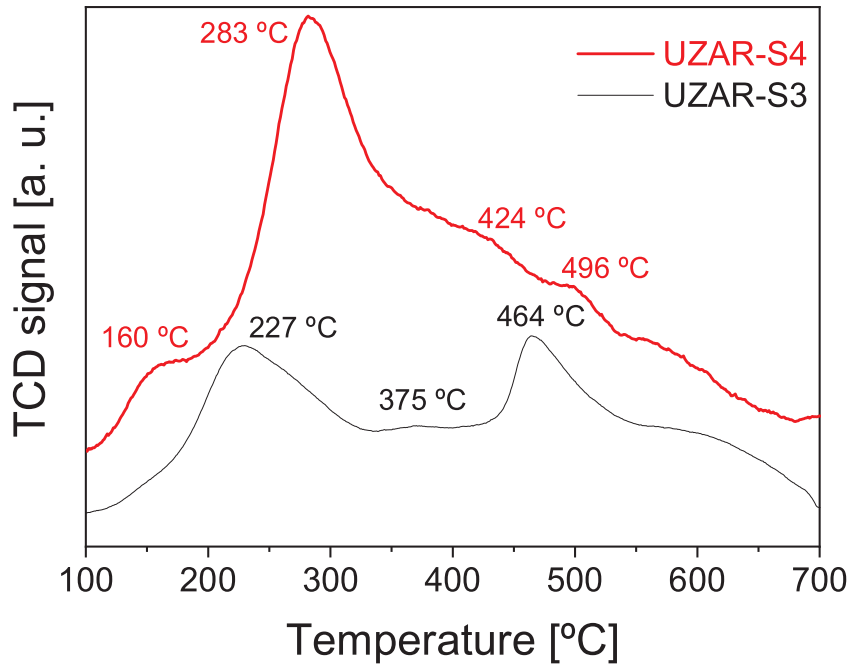

Fig. 2. $\mathrm{NH}_{3}$ TPD of UZAR-S3 and UZAR-S4.

silanol groups. This occurs in the study of some layered zeolites and silicates, where the limitations to allow pyridine access [34] are saved upon delamination, in agreement with the change of textural properties (increase of external surface area) an increase of silanols (as typically observed by solid state NMR [30]). Therefore, the TPD analysis with ammonia has been performed due to the fact that ammonia is another relatively strong basic molecule commonly used to probe acid sites in catalysts like zeolites. Ammonia, with a smaller kinetic diameter, $3.0 \AA$, than pyridine, has a greater accessibility to the pores.

The total acidity of UZAR-S3 and UZAR-S4 catalysts, as well as the strength of these acid sites, can be compared using the ammonia TPD (Fig. 2). Like other authors [23], it has been considered that peaks below $200{ }^{\circ} \mathrm{C}$, between 200 and $400{ }^{\circ} \mathrm{C}$ and above $400{ }^{\circ} \mathrm{C}$ correspond to weak, medium and strong acid sites, respectively. The total value of ammonia in UZAR-S3 is $1.45 \mathrm{mmol} \cdot \mathrm{g}^{-1}$ while in UZAR-S4 it is $2.58 \mathrm{mmol} \cdot \mathrm{g}^{-1}$. These values are consistent with what was previously seen with pyridine FTIR and UZAR-S4 show a greater amount of accessible acid sites than UZAR-S3. Moreover, the desorption temperatures observed (Fig. 2) for UZAR-S4 are $160{ }^{\circ} \mathrm{C}$ (weak), $283^{\circ} \mathrm{C}$ (medium), $424^{\circ} \mathrm{C}$ (strong) and $496^{\circ} \mathrm{C}$ (strong), whereas UZAR-S3 presents them at $227^{\circ} \mathrm{C}$ (medium), $375^{\circ} \mathrm{C}$ (medium) and $464^{\circ} \mathrm{C}$ (strong). In Fig. 2 the increase in acidity of UZAR-S4 is observed, which is related to the appearance of weak acidity and above all the increase in medium acidity.

\subsection{Catalytic results}

The results obtained in the conversion of sugars (glucose and sucrose) using UZAR-S3 and UZAR-S4 as catalysts for $20 \mathrm{~h}$ at $160{ }^{\circ} \mathrm{C}$ are shown in Table 1 and Fig. 3. In the case of glucose (Fig. 3), the yield to methyl lactate increased when the catalyst used in the reaction was swollen and later delaminated: $3.2 \%$ with UZAR-S3, $12.2 \%$ with swollen UZAR-S3 and $37.4 \%$ with UZAR-S4.

This suggests that the delamination of UZAR-S3 started with the intercalation of the amine, advancing part of the catalytic properties of the fully delaminated UZAR-S4. In addition, glucose conversion also increased from $89 \%$ to $98 \%$ (Table 1 ). This is due to the fact that delamination provides a good access of the reactants and intermediate products to catalytic sites as well as a fast desorption of products, both effects result in an increase of the catalytic activity of the material. In addition, as seen above, the catalyst UZAR-S4 has a higher proportion of acid sites, (especially medium-strength acid sites) than UZAR-S3 and these acid sites become, through delamination, accessible for large molecules. This is in agreement with the literature where the combination of Lewis and Brønsted acids along with the medium-strength 
Table 1

Catalytic results obtained for the conversion of sugars $\left(160^{\circ} \mathrm{C}, 20 \mathrm{~h}, 160 \mathrm{mg}\right.$ of catalyst and $225 \mathrm{mg}$ of sugar) with different catalysts. Methyl lactate (ML), methyl glycolate (MG), pyruvaldehyde dimethyl acetal (PADA), 1,1,2,2-tetramethoxypropane (TMP) and non-identified products (n.i.p.). Mean values and the corresponding standard deviations were calculated from 4 replicated experiments in the same operation conditions.

\begin{tabular}{|c|c|c|c|c|c|c|c|c|}
\hline \multirow[t]{2}{*}{ Catalyst } & \multirow[t]{2}{*}{ Sugar } & \multicolumn{5}{|l|}{ Yield (\%) } & \multirow{2}{*}{$\begin{array}{l}\text { Total } \\
\text { yield (\%) }\end{array}$} & \multirow{2}{*}{$\begin{array}{l}\text { Sugar } \\
\text { conv. (\%) }\end{array}$} \\
\hline & & ML & MG & PADA & TMP & n.i.p. & & \\
\hline Blank & Glucose & $1.1 \pm 0.7$ & - & $2.5 \pm 1.2$ & - & $6.0 \pm 1.7$ & 9.6 & 87 \\
\hline UZAR-S3 & Glucose & $3.2 \pm 1.3$ & $4.3 \pm 1.2$ & $1.1 \pm 0.5$ & $0.5 \pm 0.2$ & $5.6 \pm 1.2$ & 14.7 & 89 \\
\hline Swollen UZAR-S3 & Glucose & $12.2 \pm 2.5$ & $2.9 \pm 0.9$ & $3.3 \pm 0.9$ & $1.5 \pm 0.6$ & $9.2 \pm 1.0$ & 29.1 & 89.6 \\
\hline UZAR-S4 & Glucose & $37.4 \pm 3.6$ & $1.5 \pm 0.6$ & $6.2 \pm 1.3$ & $5.6 \pm 1.8$ & $7.8 \pm 1.5$ & 58.5 & 98 \\
\hline Blank & Sucrose & $1.4 \pm 0.9$ & - & $2.5 \pm 1.4$ & $0.1 \pm 0.04$ & $4.3 \pm 1.3$ & 8.3 & 88.6 \\
\hline UZAR-S3 & Sucrose & $8.0 \pm 0.6$ & $1.2 \pm 0.2$ & $0.5 \pm 0.1$ & $0.2 \pm 0.07$ & $3.8 \pm 0.3$ & 13.7 & 88.8 \\
\hline Swollen UZAR-S3 & Sucrose & $33.0 \pm 3.1$ & $0.4 \pm 0.2$ & $1.7 \pm 0.1$ & $0.6 \pm 0.2$ & $6.0 \pm 1.6$ & 41.7 & 89.5 \\
\hline UZAR-S4 & Sucrose & $49.9 \pm 9.6$ & $0.1 \pm 0.01$ & $5.3 \pm 1.1$ & $1.5 \pm 0.4$ & $6.7 \pm 1.6$ & 63.5 & 99.5 \\
\hline
\end{tabular}

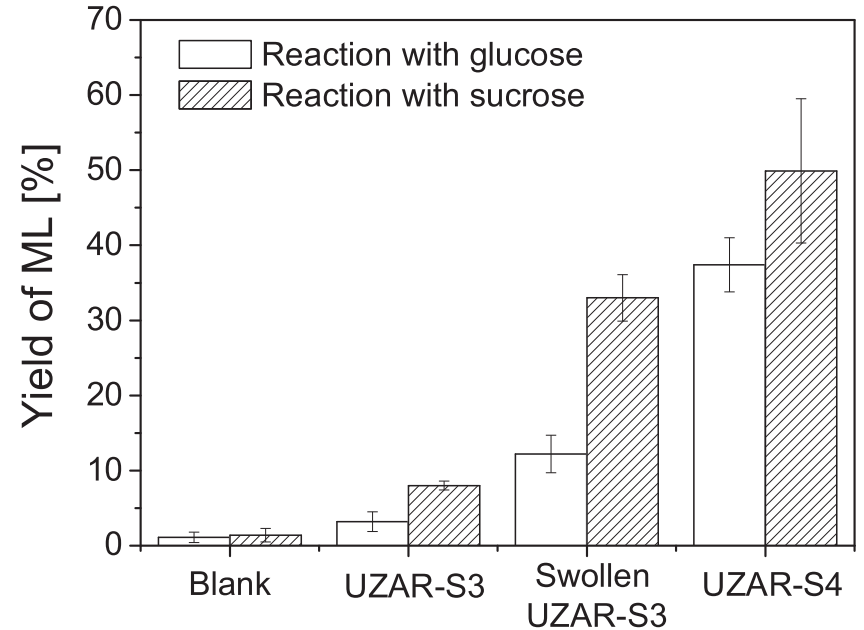

Fig. 3. ML yield obtained for the conversion of sugars $\left(160^{\circ} \mathrm{C}, 20 \mathrm{~h}, 160 \mathrm{mg}\right.$ of catalyst and $225 \mathrm{mg}$ of sugar) with different catalysts.

acid sites favors the conversion to methyl lactate [23]. Then, except for MG, the yield to other products slightly increased with the delaminated catalysts (Table 1). It should be taken into account that glucose has several reaction pathways [29], one of them produces during the retroaldol condensation erythrose and glycolaldehyde. Then, glycolaldehyde can evolve into the identified MG, and erythrose can evolve into methyl vinyl glycolate [11,35]. This last compound could be related to some of the unidentified peaks. The another pathway forms compounds with three carbon atoms (glyceraldehyde and dihydroxyacetone) that finally can be transformed into ML, PADA and TMP. Therefore, the delaminated catalyst seems to favor this second pathway but not the first.

It should also be commented that since the steric hindrances in UZAR-S4 are lower than in UZAR-S3, the formation of several bigger compounds through the kind of reactions studied here is plausible. In fact, it has been observed that the pore size in mesoporous materials (e.g. MCM-41) in comparison with materials with smaller pores (e.g. zeolite beta) can do shape-selective control [36]. However, these compounds was not detected here, although there was an increase in unidentified compounds, which could be related to them.

The same increase in ML yield was reported in the conversion of glucose with delaminated porous titanosilicates as catalysts [29]: $3.9 \%$ with UZAR-S1 and $1.8 \%$ with its precursor JDF-L1; and $5.2 \%$ with UZAR-S2 and $1.2 \%$ with its precursor AM-4. The much better results of UZAR-S4 can be attributed mainly to the presence of tin in the structure, that has a higher catalytic activity for this reaction than titanium [29].

Regarding the catalytic tests carried out with sucrose. In all cases, the yields to methyl lactate are better using sucrose instead of glucose (Fig. 3). In the case of UZAR-S3 it increases from $3.2 \%$ to $8.0 \%$, if sucrose was used instead of glucose. The swollen material shows a greater increase, from $12.2 \%$ to $33.0 \%$, due to the above mentioned incipient delamination. And delaminated material UZAR-S4 increased the yield from $37.4 \%$ to $49.9 \%$. This is because sucrose is a non-reducing sugar, which has an o-glycosidic bond that protects carbonyl groups. In this way, the release of hexoses from sucrose in solution is slow, avoiding the occurrence of unwanted side reactions with the more reactive glucose and fructose, and a less amount of by-products is generated $[26,37]$. Regarding the sugar conversion, this was similar for glucose and sucrose, being almost total with delaminated UZAR-S4.

The amount of catalyst used in the reaction was studied, keeping constant the amount of the other reagents $(225 \mathrm{mg}$ of sucrose and $8 \mathrm{~g}$ of methanol). Different experiments were performed with 50, 80, 100 and $160 \mathrm{mg}$ of catalyst. Average methyl lactate yields and standard deviations are shown in Fig. 4. It can be seen that the difference in ML yield is negligible using $100 \mathrm{mg}$ instead of $160 \mathrm{mg}$ of catalyst. Nevertheless, the ML yield decreased if the amount of catalyst was reduced to 80 or $50 \mathrm{mg}$. Therefore, $100 \mathrm{mg}$ is considered to be the optimum amount of catalyst, because the preparation of the material is expensive and it is desirable to use the smallest amount of it, while maintaining a high level of catalytic activity. With a reduction in the amount of catalyst near $40 \%$ the ML yield was reduced only a $3.3 \%$.

\subsection{Comparison with literature}

The yield to methyl lactate achieved using UZAR-S4 as catalyst was $37.4 \%$ with glucose and $49.9 \%$ with sucrose. These values are in the order of those obtained by Holm et al. [21] with Sn-beta zeolite as

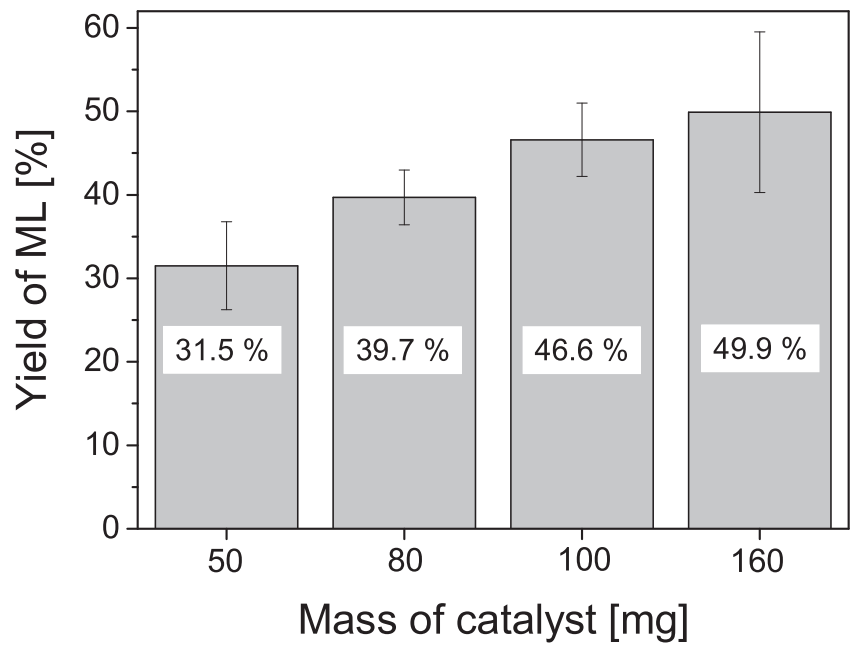

Fig. 4. ML yield in the conversion of sucrose with different amounts of UZARS4 as catalyst. Experimental conditions: $160{ }^{\circ} \mathrm{C}, 20 \mathrm{~h}$ and $225 \mathrm{mg}$ of sucrose. Error bars correspond to standard deviations from at least 3 replicated runs. 
Table 2

Literature review of methyl lactate yield from sucrose under experimental conditions analogous to those applied in this work using heterogeneous catalysts.

\begin{tabular}{|c|c|c|c|c|c|c|c|}
\hline Catalysts & $\mathrm{T}\left({ }^{\circ} \mathrm{C}\right)$ & $\mathrm{t}(\mathrm{h})$ & $\mathrm{MeOH}(\mathrm{g})$ & Sucrose (mg) & Catalysts (mg) & ML Yield & Ref \\
\hline Ti-Beta & 160 & 20 & 8 & 225 & 160 & 44 & [21] \\
\hline Zr-Beta & 160 & 20 & 8 & 225 & 160 & 40 & [21] \\
\hline Sn-Beta & 160 & 20 & 8 & 225 & 160 & 64 & [21] \\
\hline Sn-Beta & 160 & 16 & 15 & 450 & 150 & 59 & [10] \\
\hline $\operatorname{CSM}^{(1)}$ & 155 & 20 & 6 & 225 & 160 & 45 & [11] \\
\hline Sn-MWW & 160 & 20 & 4 & 112.5 & 80 & 55 & [13] \\
\hline Li-Sn-Beta & 170 & 16 & 15 & 450 & 150 & 59 & [38] \\
\hline Na-Sn-Beta & 170 & 16 & 15 & 450 & 150 & 52 & [38] \\
\hline K-Sn-Beta & 170 & 16 & 15 & 450 & 150 & 66 & [38] \\
\hline Rb-Sn-Beta & 170 & 16 & 15 & 450 & 150 & 67 & [38] \\
\hline Cs-Sn-Beta & 170 & 16 & 15 & 450 & 150 & 62 & [38] \\
\hline Sn-Beta- $\mathrm{WO}_{3}$ & 160 & 5 & 12 & 320 & 200 & 60 & [39] \\
\hline ZIF-8 & 160 & 24 & 8 & 225 & 160 & 34.8 & [26] \\
\hline Hierarchical Sn-Beta & 160 & 20 & 8 & 225 & 160 & 72.1 & [22] \\
\hline Fe-doped $\mathrm{SnO}_{2}$ & 160 & 20 & 16 & 220 & 160 & 44 & [23] \\
\hline Mg-MOF-74 & 220 & 6 & 7 & 60 & 20 & 47 & [24] \\
\hline MIP-177-LT (Ti/Sn) & 160 & 24 & 8 & 225 & 160 & 39.4 & [27] \\
\hline$\gamma-\mathrm{NiOOH}$ & 200 & 12 & 40 & 400 & 200 & 38.7 & [25] \\
\hline UZAR-S4 & 160 & 20 & 8 & 225 & 160 & 49.9 & This work \\
\hline
\end{tabular}

(1) CSM: Carbon silica composite material.

catalyst: $44 \%$ for glucose and $64 \%$ for sucrose and the yield value reached with Sn-MCM-41 $43 \%$ for glucose [29]. Table 2 shows a review of heterogeneous catalysts with featured results in the conversion of sucrose to methyl lactate. This table includes results with reaction conditions similar to those tested here.. The performance of this work is among the best in the literature, the zeolite Sn-beta based catalysts being those that have achieved the best results to date. Specifically, the highest yield corresponds to a Sn-beta zeolite with hierarchical pore structure that favors the access and desorption of compounds in the catalytic sites, as occurs as a result of the exfoliation strategy followed here.

\subsection{Reusability of UZAR-S4}

The interest of a heterogeneous catalyst is in its reusability, therefore the UZAR-S4 solid was used in three consecutive catalytic cycles of sucrose transformation using $100 \mathrm{mg}$ of catalysts. Between the catalytic cycles, the catalyst was dried in the oven at $150^{\circ} \mathrm{C}$ for $12 \mathrm{~h}$ in order to remove weakly adsorbed compounds.

The yield to different products during 3 catalytic cycles is shown in Fig. 5. It can be seen that when reusing UZAR-S4 catalyst in a second catalytic cycle the ML yield slightly decreased by only $4 \%$ (from $46.6 \%$ to $42.6 \%$ ). However, a third catalytic cycle implied a loss of catalytic

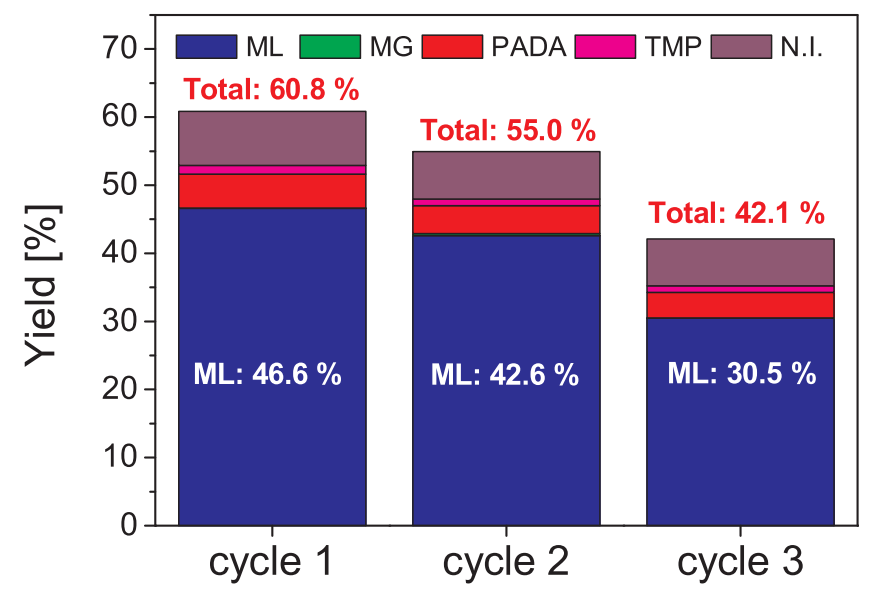

Fig. 5. Yield of different products in the conversion of sucrose with UZAR-S4 up to 3 catalytic cycles. Experiment conditions: $160^{\circ} \mathrm{C}, 20 \mathrm{~h}, 100 \mathrm{mg}$ of catalyst and $225 \mathrm{mg}$ of sugar. activity, the yield to ML decreasing by up to $30.5 \%$. Therefore, the physical-chemical changes that occurred in the catalyst during its use were studied to find out the reasons for this deactivation. The other products remained practically constant during the successive catalytic cycles performed.

\subsection{Characterization of catalyst after catalytic cycles}

The X-ray diffractograms of UZAR-S4 before and after one catalytic test with sucrose are shown in Fig. 6a. As can be observed, UZAR-S4 has the XRD features corresponding to an amorphous material and no appreciable changes occurred during the reaction. It should be noted that other porous delaminated materials also show an amorphous X-ray diffractogram [40], but in the specific case of the UZAR-S4 material the electron diffraction performed from some crystallites suggests that the structure would be maintained at some extension respect to the UZARS3 material [30].

In the thermogravimetric analysis performed and shown in Fig. $6 \mathrm{~b}$, it can be seen that the weight loss curve of fresh UZAR-S4 is clearly different from that of the recovered solid after reaction. UZAR-S4 before the reaction has a main loss below $100^{\circ} \mathrm{C}$ due to adsorbed solvents (water and ethanol), while in the case of UZAR-S4 after the reaction the curve present several weight losses above $100{ }^{\circ} \mathrm{C}$ due to adsorption of carbonaceous compounds on the surface of UZAR-S4 during the reaction.

Fig. 7 shows the SEM images of UZAR-S4 before and after reaction with sucrose. The external morphology of UZAR-S4 is evident in Fig. 7a of sheets with a thickness of ca. $100 \mathrm{~nm}$. After reaction, in general, there were no substantial changes in the appearance of the particles although some particles seem to have been fragmented.

In addition to SEM, energy dispersive X-ray spectroscopy (EDX) was performed to the same samples. $\mathrm{Si} / \mathrm{Sn}$ atomic ratio of fresh UZAR-S4 was $39 \pm 17$ and $\mathrm{Si} / \mathrm{Sn}$ ratio of the solid recovered after reaction with sucrose was $42 \pm 16$. Variations may indicate leaching of tin in the reaction solution but the variation is in the error and cannot be affirmed emphatically. This leachate could be the cause of the loss of catalytic activity but as will be seen below there were more relevant textural changes in the catalyst during reaction. Given the high methyl lactate yield, the contribution of catalytic activity in homogeneous phase of this possible low amount of tin in the solution would have low influence on the catalytic results.

Table 3 shows the textural properties of UZAR-S4 material before and after the reaction with sucrose for each catalytic cycle. There is a 

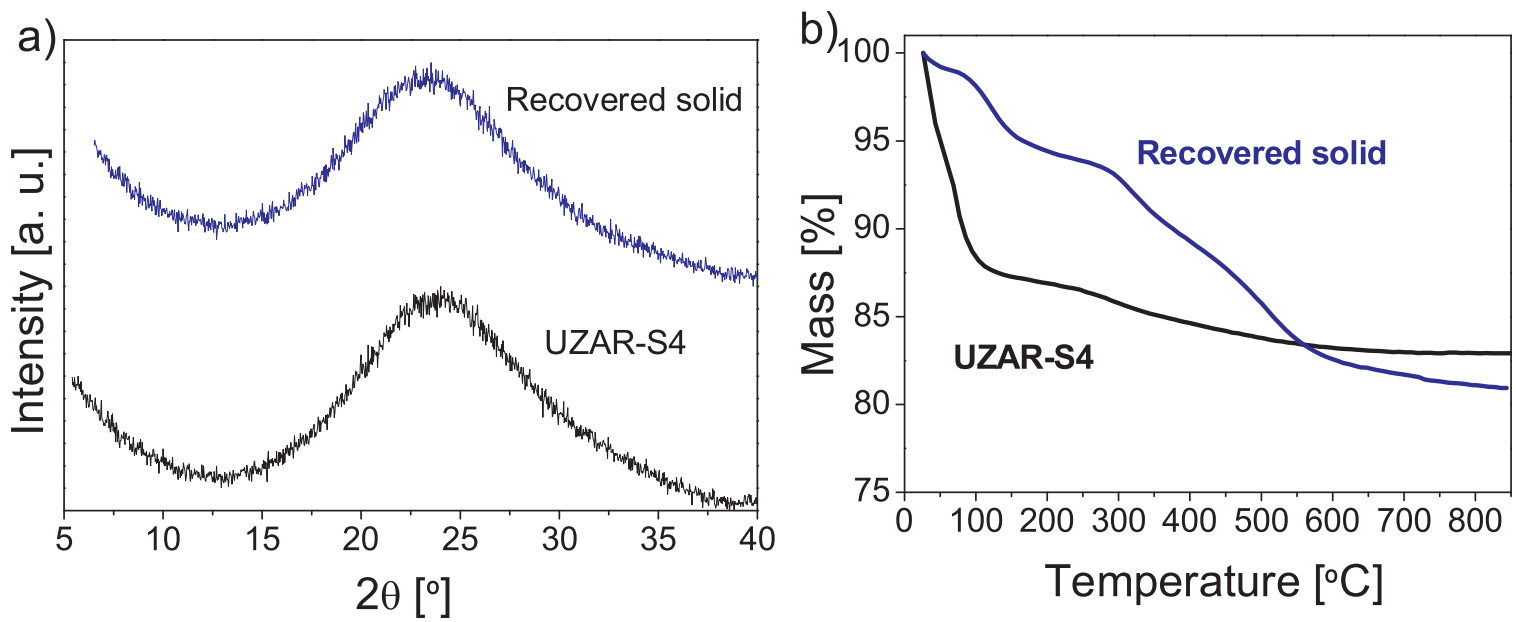

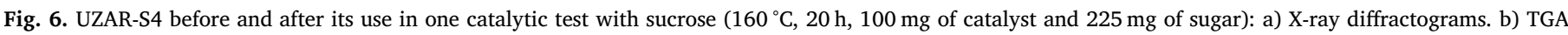
curves.

slight decrease in the BET area after the first cycle (from 352 to $315 \mathrm{~m}^{2} \cdot \mathrm{g}^{-1}$ ) and also in the pore volume (from 0.25 to $0.22 \mathrm{~cm}^{3} \cdot \mathrm{g}^{-1}$ ). This fact could be attributed to the compounds adsorbed in the catalyst (in line with the TGA curves in Fig. 6b), a deterioration of catalyst structure and a change in its chemical composition due to leaching. Degasification prior to the measure of nitrogen isotherms was carried out at $200{ }^{\circ} \mathrm{C}$, nevertheless in the TGA curve of the recovered solid after reaction with sucrose there is a weight loss of $13.5 \%$ from $200{ }^{\circ} \mathrm{C}$. This suggests that certain adsorbed compounds (reaction products) could decrease both surface area and pore volume. After the second and third cycles, the decrease in the specific surface area and pore volume became greater, indicating a further degradation of the material UZAR-S4 with the continued use. This loss of textural properties after the second cycle is in agreement with the decrease in ML yield (see Fig. 5).

\section{Conclusions}

Stannosilicate UZAR-S4 was successfully synthesized by delamination of UZAR-S3. This material can be applied as catalyst for the conversion of glucose and sucrose with high activity and selectivity to methyl lactate. The higher ML yield was $49.9 \%$ in the conversion of sucrose at $160{ }^{\circ} \mathrm{C}$ for $20 \mathrm{~h}$ with $160 \mathrm{mg}$ of catalyst with a conversion of sugar near $100 \%$. Furthermore, the delamination of the catalyst increases its activity (ML yield increased from $8.0 \%$ for UZAR-S3 to 49.9 $\%$ with UZAR-S4 in the conversion of sucrose) because it improves the access of reactants and intermediate products to catalytic sites. In
Table 3

Textural properties of UZAR-S4 fresh and after each catalytic cycle. Pore volume measured at $\mathrm{P} / \mathrm{P}_{0}=0.97$.

\begin{tabular}{lll}
\hline Sample & BET specific surface area $\left[\mathrm{m}^{2} \mathrm{~g}^{-1}\right]$ & Pore volume $\left[\mathrm{cm}^{3} \mathrm{~g}^{-1}\right]$ \\
\hline Fresh UZAR-S4 & $352 \pm 38$ & 0.35 \\
After cycle 1 & $315 \pm 15$ & 0.29 \\
After cycle 2 & $174 \pm 16$ & 0.22 \\
After cycle 3 & $89 \pm 5$ & 0.12 \\
\hline
\end{tabular}

addition, the catalytic acid sites have the appropriate combination of Lewis and Brønsted acid sites and in UZAR-S4 the medium-strength acid sites are greater compared to those in UZAR-S3. Regarding its stability, UZAR-S4 was reused up to three times, with a reduction of methyl lactate yield that can be explained by the degradation of the material in the reaction medium in agreement with the decrease of specific surface area. UZAR-S4 can be considered an interesting material in the conversion of sugars since the results obtained are in the order or even better than those reported before with other heterogeneous catalysts.

\section{CRediT authorship contribution statement}

Beatriz Murillo: Investigation, Methodology, Formal analysis, Writing - original draft. Óscar de la Iglesia: Investigation, Methodology, Formal analysis, Writing - original draft, Writing - review \& editing, Visualization. César Rubio: Investigation, Methodology,
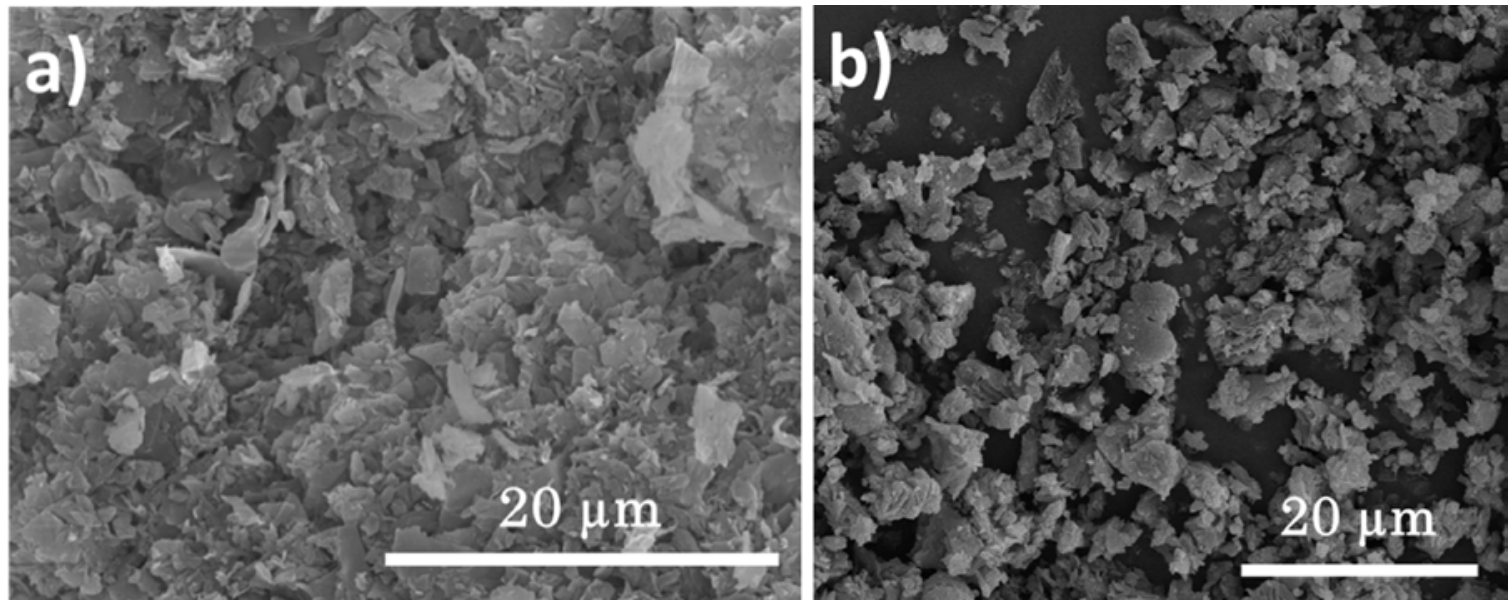

Fig. 7. SEM images of UZAR-S4: a) before reaction; b) after reaction with sucrose $\left(160^{\circ} \mathrm{C}, 20 \mathrm{~h}, 100 \mathrm{mg}\right.$ of catalyst and $225 \mathrm{mg}$ of sugar). 
Formal analysis, Writing - original draft, Writing - review \& editing. Joaquín Coronas: Conceptualization, Methodology, Supervision, Project administration, Funding acquisition, Writing - original draft, Writing - review \& editing. Carlos Téllez: Conceptualization, Methodology, Supervision, Project administration, Funding acquisition, Writing - original draft, Writing - review \& editing.

\section{Declaration of Competing Interest}

The authors declare that they have no known competing financial interests or personal relationships that could have appeared to influence the work reported in this paper.

\section{Acknowledgements}

Financial support from the Research Projects MAT2016-77290-R (AEI/FEDER, UE) and T43-17R (the Aragón Government and the ESF) is gratefully acknowledged. The authors would like to acknowledge the University of Zaragoza for the use of the Servicio General de Apoyo a la Investigación-SAI and the Laboratorio de Microscopías Avanzadas (LMA) at INA

\section{References}

[1] F.A. Castillo Martinez, E.M. Balciunas, J.M. Salgado, J.M. Domínguez González, A. Converti, R.P. de S. Oliveira, Lactic acid properties, applications and production: a review, Trends Food Sci. Technol. 30 (2013) 70-83, https://doi.org/10.1016/j. tifs.2012.11.007.

[2] M.A. Abdel-Rahman, Y. Tashiro, K. Sonomoto, Lactic acid production from lignocellulose-derived sugars using lactic acid bacteria: overview and limits, J. Biotechnol. 156 (2011) 286-301, https://doi.org/10.1016/j.jbiotec.2011.06.017.

[3] W.S. Chow, E.L. Teoh, J. Karger-Kocsis, Flame retarded poly(lactic acid): a review, Express Polym. Lett. 12 (2018) 396-417 https://doi.org/10.3144/ expresspolymlett.2018.34.

[4] R. De Clercq, M. Dusselier, B.F. Sels, Heterogeneous catalysis for bio-based polyester monomers from cellulosic biomass: advances, challenges and prospects, Chem Sus. Chem. 19 (2017) 5012-5040, https://doi.org/10.1039/C7GC02040F.

[5] M. Dusselier, P. Van Wouwe, A. Dewaele, E. Makshina, B.F. Sels, Lactic acid as a platform chemical in the biobased economy: the role of chemocatalysis, Energy Environ. Sci. 6 (2013) 1415-1442, https://doi.org/10.1039/c3ee00069a.

[6] Y. Hayashi, Y. Sasaki, Tin-catalyzed conversion of trioses to alkyl lactates in alcohol solution, Chem. Comm. 21 (2005) 2716-2718, https://doi.org/10.1039/b501964h.

[7] L. Zhou, L. Wu, H. Li, X. Yang, Y. Su, T. Lu, J. Xu, A facile and efficient method to improve the selectivity of methyl lactate in the chemocatalytic conversion of glucose catalyzed by homogeneous Lewis acid, J. Mol. Catal. A. 388-389 (2014) 74-80, https://doi.org/10.1016/j.molcata.2014.01.017.

[8] J.B. dos Santos, N. Albuquerque, C.L.P.S. Zanta, M.R. Meneghetti, S. Plentz Meneghetti, Fructose conversion in the presence of Sn(IV) catalyst exhibiting high selectivity to lactic acid, RSC Adv. 5 (2015) 90952-90959, https://doi.org/10. 1039/b000000x.

[9] K.P.F. Janssen, J.S. Paul, B.F. Sels, P.A. Jacobs, Glyoxylase biomimics: zeolite catalyzed conversion of trioses, Stud. Surf. Sci. Catal. 170 (2007) 1222-1227 https:// doi.org/10.1016/S0167-2991(07)80981-5.

[10] C.M. Osmundsen, M.S. Holm, S. Dahl, E. Taarning, Tin-containing silicates: struc ture-activity relations, Proc. R. Soc. A Math. Phys. Eng. Sci. 468 (2012) 2000-2016, https://doi.org/10.1098/rspa.2012.0047.

[11] F. De Clippel, M. Dusselier, R. Van Rompaey, P. Vanelderen, J. Dijkmans, E. Makshina, L. Giebeler, S. Oswald, G.V. Baron, J.F.M. Denayer, P.P. Pescarmona, P.A. Jacobs, B.F. Sels, Fast and selective sugar conversion to alkyl lactate and lactic acid with bifunctional carbon - silica catalysts, J. Am. Chem. Soc. 134 (2012) 10089-10101, https://doi.org/10.1021/ja301678w.

[12] L. Li, X. Collard, A. Bertrand, B.F. Sels, P.P. Pescarmona, C. Aprile, Extra-small porous Sn-silicate nanoparticles as catalysts for the synthesis of lactates, J. Catal. 314 (2014) 56-65, https://doi.org/10.1016/j.jcat.2014.03.012.

[13] Q. Guo, F. Fan, E.A. Pidko, W.N.P. Van Der Graaff, Z. Feng, C. Li, Highly active and recyclable Sn-MWW zeolite catalyst for sugar conversion to methyl lactate and lactic acid, Chem. Sus. Chem. 6 (2013) 1352-1356, https://doi.org/10.1002/cssc 201300160.

[14] N. Godard, A. Vivian, L. Fusaro, L. Cannavicci, C. Aprile, D.P. Debecker, High-yield synthesis of ethyl lactate with mesoporous tin silicate catalysts prepared by an aerosol-assisted sol-gel process, Chem. Cat. Chem. 9 (2017) 2211-2218, https:// doi.org/10.1002/cctc.201601637.

[15] X. Wang, Y. Song, L. Huang, H. Wang, C. Huang, C. Li, Tin modified $\mathrm{Nb}_{2} \mathrm{O}_{5}$ as an efficient solid acid catalyst for the catalytic conversion of triose sugars to lactic acid, Catal. Sci. Technol. 9 (2019) 1669-1679, https://doi.org/10.1039/c9cy00257j.

[16] S. Yamaguchi, M. Yabushita, M. Kim, J. Hirayama, K. Motokura, A. Fukuoka, K. Nakajima, Catalytic conversion of biomass-derived carbohydrates to methyl lactate by acid-base bifunctional $\gamma-\mathrm{Al}_{2} \mathrm{O}_{3}$, ACS Sustain. Chem. Eng. 6 (2018) 8113-8117, https://doi.org/10.1021/acssuschemeng.8b00809.

[17] K. Nakajima, J. Hirata, M. Kim, N.K. Gupta, T. Murayama, A. Yoshida, N. Hiyoshi, A. Fukuoka, W. Ueda, Facile formation of lactic acid from a triose sugar in Water over niobium oxide with a deformed orthorhombic phase, ACS Catal. 8 (2018) 283-290, https://doi.org/10.1021/acscatal.7b03003.

[18] X. Wang, F. Liang, C. Huang, Y. Li, B. Chen, Highly active tin(IV) phosphate phase transfer catalysts for the production of lactic acid from triose sugars, Catal. Sci. Technol. 5 (2015) 4410-4421, https://doi.org/10.1039/c5cy00647c.

[19] X. Wang, Y. Song, C. Huang, B. Wang, Crystalline niobium phosphates with watertolerant and adjustable Lewis acid sites for the production of lactic acid from triose sugars, Sustain. Energy Fuels. 2 (2018) 1530-1541, https://doi.org/10.1039/ c8se00140e.

[20] L. Li, F. Shen, R.L. Smith, X. Qi, Quantitative chemocatalytic production of lactic acid from glucose under anaerobic conditions at room temperature, Green Chem. 19 (2017) 76-81, https://doi.org/10.1039/c6gc02443b.

[21] M.S. Holm, S. Saravanamurugan, E. Taarning, Conversion of sugars to lactic acid derivatives using heterogeneous zeotype catalysts, Science 328 (2010) 602-605, https://doi.org/10.1126/science.1183990.

[22] J. Zhang, L. Wang, G. Wang, F. Ghen, C. Wang, C. Bian, S. Pan, F. Xiao, Hierarchical Sn-Beta zeolite catalyst for the conversion of sugars to alkyl lactates, ACS Sustain. Chem. Eng. 5 (2017) 3123-3131, https://doi.org/10.1021/acssuschemeng. 6b02881.

[23] X. Zhao, T. Wen, J. Zhang, J. Ye, Z. Ma, H. Yuan, X. Ye, Y. Wang, Fe-doped $\mathrm{SnO}_{2}$ catalysts with both BA and la sites: facile preparation and biomass carbohydrates conversion to methyl lactate MLA, RSC Adv. 7 (2017) 21678-21685, https://doi. org/10.1039/c7ra01655g.

[24] X. Lu, L. Wang, X. Lu, Catalytic conversion of sugars to methyl lactate over MgMOF-74 in near-critical methanol solutions, Catal. Commun. 110 (2018) 23-27, https://doi.org/10.1016/j.catcom.2018.02.027.

[25] X. Lyu, L. Wang, X. Chen, L. Xu, J. Wang, S. Deng, X. Lu, Enhancement of catalytic activity by $\gamma-\mathrm{NiOOH}$ for the production of methyl lactate from sugars in nearcritical methanol solutions, Ind. Eng. Chem. Res. 58 (2019) 3659-3665, https://doi. org/10.1021/acs.iecr.8b06367.

[26] B. Murillo, B. Zornoza, O. de la Iglesia, C. Téllez, J. Coronas, Chemocatalysis of sugars to produce lactic acid derivatives on zeolitic imidazolate frameworks, J. Catal. 334 (2016) 60-67, https://doi.org/10.1016/j.jcat.2015.11.016.

[27] B. Murillo, B. Zornoza, O. de la Iglesia, S. Wang, C. Serre, C. Téllez, J. Coronas, Tin carboxylate MOFs for sugar transformation into methyl lactate, Eur. J. Inorg. Chem. (2019) 2624-2629, https://doi.org/10.1002/ejic.201900310.

[28] A. Corma, V. Fornés, S.B. Pergher, T.L.M. Maesen, J.G. Buglass, Delaminated zeolite precursors as selective acidic catalysts, Nature 396 (1998) 353-356 https://doi. org/10.1038/24592.

[29] B. Murillo, A. Sánchez, V. Sebastián, C. Casado-Coterillo, O. de la Iglesia, M.P. López-Ram- de-Viu, C. Téllez, J. Coronas, Conversion of glucose to lactic acid derivatives with mesoporous Sn-MCM-41 and microporous titanosilicates, J. Chem. Technol. Biotechnol. 89 (2014) 1344-1350, https://doi.org/10.1002/jctb.4210.

[30] C. Rubio, B. Murillo, C. Casado-Coterillo, Á. Mayoral, C. Téllez, J. Coronas, Á. Berenguer-Murcia, D. Cazorla-Amorós, Development of exfoliated layered stannosilicate for hydrogen adsorption, Int. J. Hydrog. Energy. 39 (2014) 13180-13188, https://doi.org/10.1016/j.ijhydene.2014.06.149.

[31] J. Rocha, Z. Lin, Microporous mixed octahedral-pentahedral-tetrahedral framework silicates, Rev. Mineral. Geochemistry. 57 (2005) 173-201, https://doi.org/10. 2138/rmg.2005.57.6.

[32] J. Pang, M. Zheng, X. Li, L. Song, R. Sun, J. Sebastian, A. Wang, J. Wang, X. Wang, T. Zhang, Catalytic conversion of carbohydrates to methyl lactate using isolated Tin sites in SBA-15, ChemistrySelect. 2 (2017) 309-314, https://doi.org/10.1002/slct 201601752.

[33] S.A. Bradley, R.W. Broach, T.M. Mezza, S. Prabhakar, W. Sinkler, Zeolite characterization, in: S. Kulprathipanja (Ed.), Zeolite Ind. Sep. Catal. Wiley, 2010, pp. 85-171, , https://doi.org/10.1002/9783527629565.

[34] J.A.Z. Pieterse, S. Veefkind-Reyes, K. Seshan, L. Domokos, J.A. Lercher, On the accessibility of acid sites in ferrierite for pyridine, J. Catal. 187 (1999) 518-520, https://doi.org/10.1006/jcat.1999.2629.

[35] J. Iglesias, J. Moreno, G. Morales, J.A. Melero, P. Juárez, M. López-Granados, R. Mariscal, I. Martínez-Salazar, Sn-Al-USY for the valorization of glucose to methyl lactate: switching from hydrolytic to retro-aldol activity by alkaline ion exchange, Green Chem. 21 (2019) 5876-5885, https://doi.org/10.1039/c9gc02609f.

[36] M. Dusselier, P. Van Wouwe, A. Dewaele, P.A. Jacobs, B.F. Sels, Shape-selective zeolite catalysis for bioplastics production, Science 349 (2015) 78-80, https://doi. org/10.1126/science.aaa7169.

[37] M. Dusselier, B.F. Sels, Selective catalysis for cellulose conversion to lactic acid and other $\alpha$-hydroxy acids, Top. Curr. Chem. 353 (2014) 85-125, https://doi.org/10. $1007 / 128 \_2014$ _540.

[38] S. Tolborg, I. Sádaba, C.M. Osmundsen, P. Fristrup, M.S. Holm, E. Taarning, Tincontaining silicates : alkali salts improve methyl lactate yield from sugars, Chem. Sus. Chem. 8 (2015) 613-617, https://doi.org/10.1002/cssc.201403057.

[39] X. Yang, Y. Zhang, L. Zhou, B. Gao, T. Lu, Y. Su, J. Xu, Production of lactic acid derivatives from sugars over post-synthesized Sn-beta zeolite promoted by $\mathrm{WO}_{3}$ Food Chem. 289 (2019) 285-291, https://doi.org/10.1016/j.foodchem.2019.03. 039.

[40] A. Corma, V. Fornés, U. Díaz, ITQ-18 a new delaminated stable zeolite, Chem Commun. 6 (2001) 2642-2643, https://doi.org/10.1039/b108777k. 